\title{
The American Heart Association/American College of Cardiology Foundation guideline for coronary artery bypass grafting: 2011 updates
}

\author{
John G. Byrne, MD, and Marzia Leacche, MD
}

The American College of Cardiology Foundation and the American Heart Association have now updated the Practice Guidelines for coronary artery bypass grafting (CABG) surgery. ${ }^{1}$ These guidelines were developed with, and endorsed by, the American Association for Thoracic Surgery, the Society of Cardiovascular Anesthesiologists, and the Society for Thoracic Surgeons (STS).

The initial guidelines for CABG surgery were published in $1991^{2}$ and later revised in 1999 and $2004 .^{3-5}$ With the evolution in the surgical approach to coronary artery disease (CAD) and significant advances in percutaneous coronary intervention (PCI) technology, the current CABG guidelines are now internally consistent with the American College of Cardiology/American Heart Association consensus guidelines for PCI. The process to arrive at these consistent guidelines involved combining some of the writing committees from both the CABG and PCI groups to reach a broad consensus on the revascularization guidelines.

With advances in stent technology, the indications to perform PCI have expanded. This is reflected by recommendations concerning the use of stents for the treatment of left main disease. Although $\mathrm{CABG}$ surgery remains the reference standard for the treatment of left main disease, PCI has gained some value, especially for patients who are not ideal surgical candidates (eg, the very elderly with multiple co-morbidities) and has become a reasonable alternative to $\mathrm{CABG}$ for selected patients: The current guideline now suggest that "those with (1) anatomic conditions associated with a low risk of PCI procedural complications and a high likelihood of good long-term outcome (eg, a low SYNTAX score of $\leq 22$, ostial or trunk left main CAD); and (2) clinical characteristics that predict a significantly increased risk of adverse surgical outcomes (eg, STS [risk score] predicted operative mortality $\geq 5 \%$ )" (class IIa, level of evidence B), might benefit from left main PCI.

The new guidelines also introduced the role of SYNTAX scores as a method of documenting the extent and

\footnotetext{
From the Vanderbilt Heart and Vascular Institute, Nashville, Tenn. Disclosures: Authors have nothing to disclose with regard commercial support. Address for reprints: John G. Byrne, MD, Department of Cardiac Surgery, Vanderbilt University Medical Center, Nashville, TN 37232-8802 (E-mail: john.byrne@ vanderbilt.edu)

J Thorac Cardiovasc Surg 2012;143:35-46

0022-5223/\$36.00

Copyright (c) 2012 by The American Association for Thoracic Surgery doi:10.1016/j.jtcvs.2011.11.033
}

complexity of CAD. This, together with the patient's surgical risk profile (STS score), can further guide clinical decision making. Although limitations exist with using the SYNTAX score and the STS predicted risk mortality algorithm, the use of both scores is an important piece of information that the clinicians should consider when deciding the modality of revascularization.

With the variety of technology now available, and those being currently investigated (eg, transcatheter aortic valve), the new guidelines stress the increased need to evaluate the patient using a team approach ("the heart team"-composed of a general cardiologist, an interventional cardiologist, and a cardiac surgeon) instead of individual practitioners. As a consequence, a more comprehensive decision regarding the revascularization strategy/options taking into account the outcomes of a particular procedure for the full cycle of care for a medical condition can be undertaken. With this heart team approach, for example, the current guidelines now recommend "particularly in patients with stable ischemic heart disease and unprotected left main disease and/or complex CAD in whom a revascularization strategy is not straightforward, an approach that involves terminating the procedure after diagnostic coronary angiography is completed so as to allow a complete discussion and afford both the interventional cardiologist and cardiac surgeon the opportunity to discuss revascularization options."1

Surgeons and cardiologists are encouraged to use the SYNTAX score and the STS score as a method to measure and quantify more objectively the complexity of the coronary anatomy and the surgical risk is useful in making heart team revascularization decisions. In real life practice, however, most of the time, the individual practitioner would make the decision regarding the modality of revascularization.

The CABG guidelines also formally introduced hybrid $\mathrm{CABG} / \mathrm{PCI}$ in the surgical/interventional armamentarium for treating CAD. The premise of hybrid CABG/PCI is that the left internal mammary artery to the left anterior descending artery (LAD) is the superior modality of coronary revascularization; thus, for non-LAD vessels, PCI might be a better option than saphenous vein grafts owing to the better patency rate of drug-eluting stents compared to saphenous vein grafts. The guidelines now indicate that "hybrid coronary revascularization (defined as the planned combination of left internal mammary artery-to-LAD artery grafting and PCI of $\geq 1$ non-LAD coronary arteries) is 
reasonable in patients with $\geq 1$ of the following: (1) limitations to traditional CABG, such as a heavily calcified proximal aorta or poor target vessels for CABG (but amenable to PCI); (2) lack of suitable graft conduits; (3) unfavorable LAD artery for PCI (ie, excessive vessel tortuosity or chronic total occlusion)" (class IIa, level of evidence B). The indications to perform hybrid CABG/PCI as an alternative to standard CABG or multivessel PCI are not yet established, because the available data are limited and mostly from single-institution retrospective studies. Although the preliminary data have indicated a potential for the hybrid strategy to become a superior and novel revascularization alternative in multivessel CAD, the true clinical effect of this approach will not be known until we have data from randomized clinical trials.

In conclusion, these new guidelines reflect the new era of CABG surgery and PCI, together representing American Heart Association/American College of Cardiology guidelines for coronary revascularization, in which the boundaries between PCI and CABG have become blurred. With the increasing complexity of the patients referred to surgery and intervention, with healthcare reform looming, compar- ative effectiveness studies are needed regarding the different revascularization modalities, their long-term financial effect on society, and the overall value to the patient.

\section{References}

1. 2011 ACCF/AHA Guidelines for Coronary Artery Bypass Grafting Surgery: Executive Committee. J Thorac Cardiovasc Surg. 2012;143:4-34.

2. Kirklin JW, Akins CW, Blackstone EH, et al. Guidelines and indications for coronary artery bypass graft surgery: a report of the American College of Cardiology/ American Heart Association Task Force on Assessment of Diagnostic and Therapeutic Cardiovascular Procedures (Subcommittee on Coronary Artery Bypass Graft Surgery). J Am Coll Cardiol. 1991;17:543-89.

3. Eagle KA, Guyton RA, Davidoff R, et al. ACC/AHA 2004 guideline update for coronary artery bypass graft surgery: a report of the American College of Cardiology/American Heart Association Task Force on Practice Guidelines (Committee to Update the 1999 Guidelines for Coronary Artery Bypass Graft Surgery). Circulation. 2004; 110:e340-437.

4. Kirklin JW, Akins CW, Blackstone EH, et al. Guidelines and indications for coronary artery bypass graft surgery: a report of the American College of Cardiology/ American Heart Association Task Force on Assessment of Diagnostic and Therapeutic Cardiovascular Procedures (Subcommittee on Coronary Artery Bypass Graft Surgery). J Am Coll Cardiol. 1991;17:543-89.

5. Eagle KA, Guyton RA, Davidoff R, et al. ACC/AHA guidelines for coronary artery bypass graft surgery: a report of the American College of Cardiology/American Heart Association Task Force on Practice Guidelines (Committee to Revise the 1991 Guidelines for Coronary Artery Bypass Graft Surgery). American College of Cardiology/American Heart Association. J Am Coll Cardiol. 1999;34: 1262-347. 